\title{
OBTAINING COMPLEX COAGULANTS FROM WASTE OF METALLURGICAL PLANTS
}

\author{
${ }^{1}$ Evgenii KUZIN, ${ }^{1}$ Natalya KRUCHININA, ${ }^{1}$ Julia AVERINA, ${ }^{1}$ Andrey KURBATOV, \\ ${ }^{1}$ Tatyana NOSOVA
}

${ }^{1}$ D.Mendeleev University of Chemical Technology of Russia, Moscow, Miusskaya pl. 9, 125047, Russia, e.n.kuzin@mail.ru

https://doi.org/10.37904/metal.2020.3451

\begin{abstract}
The processes of production of pig iron, steel and cast irons are accompanied by the formation of a significant amount of slag. This waste can be sent to re-smelting, however, if it contains a high content of impurity components, it is sent to the dump as waste. This waste contains $40-50 \%$ of iron compounds, with a developed surface. In the framework of the work, it is proposed to use slag as a feedstock to obtain complex coagulants. Complex coagulants are highly effective reagents used in wastewater treatment processes for hydrotreating parts, gas purification, and also galvanic wastewater. As part of the studies, the high efficiency of complex coagulants in the processes of wastewater treatment of galvanic production from chromium (VI) ions was confirmed.
\end{abstract}

Keywords: Recycle, slag, water treatment, complex coagulant, wastewater

\section{INTRODUCTION}

All processes associated with metallurgical production have a significant impact on the natural environment. Steel smelting processes are accompanied by huge emissions of gases and dust into the atmosphere, significant amounts of water consumption for various purposes (for example, cooling furnaces, hydrotreating surfaces of parts, processes for capturing exhaust gases), as well as the formation of huge amounts of various wastes.

Most of the waste generated during metal smelting or its processing (quenching, pressure treatment) due to the high content of the source metal is returned to production. The dross formed during the heat treatment of parts for $90-95 \%$ consists of iron oxides and can be used as an additive to raw materials in steel smelting processes [1-3]. Demetallized steelmaking slag can be use as charge of basic oxygen converter [4].

Despite the high degree of use and recycling of such waste, there is a part of slag and scale, which, due to the high degree of contamination, cannot be reused. Typically, this waste is placed on the slag dump of the enterprise or used as an additive to building materials or used in the processes of road construction [5].

Another environmental problem associated with the production and processing of steel products is the wastewater of the plating process. Wastewater containing copper, nickel, cadmium and zinc ions is neutralized and purified by precipitation of insoluble metal hydroxides. Wastewater from etching processes is the most difficult case, since chromates are highly soluble in a wide $\mathrm{pH}$ range and cannot be removed by traditional methods (neutralization, coagulation) [6]. To clean such effluents, chromium (VI) ions are reduced (by iron (II) salt or sulphurous acid's salts) to chromium (III) and only then insoluble hydroxides are precipitated. Usually, iron (II) or sulfuric acid salts are used as reducing agents [7]. The resulting chromium (II) compounds are removed by precipitation in the form of insoluble hydroxides, and aluminum, iron or titanium-containing coagulants can be used to intensify the process [8-9]. 
Another waste generated in significant quantities is spent solutions for etching and cleaning the surfaces of plating areas.

The main goal of this work is to develop a technology for processing slag from the electric arc steelmaking process and spent solutions of anodic etching of titanium in order to obtain complex reducing coagulants for the treatment of wastewater from galvanic production from chromium (VI) ions. The result will have a high environmental effect, will improve the efficiency of wastewater treatment and will help reduce the amount of waste generated through the use of waste as raw materials for the production of a comprehensive reagent for wastewater treatment of galvanic production.

\section{METODS OF ANALYSES}

Slag samples were preliminarily crushed to a size of $40-60 \mu \mathrm{m}$ in a planetary mill, followed by averaging of the composition and tableting.

Sulfate solutions of anodic etching of titanium parts were selected as the feedstock for the synthesis of a complex coagulant reducing agent. The presence of titanium compounds in the obtained samples of the complex coagulant-reducing agent will further increase the efficiency of coagulation wastewater treatment [10-11].

The chemical composition of solid samples was determined by X-ray fluorescence analysis on a JEOL 1610LV scanning electron microscope with an energy-dispersive spectrometer for electron probe microanalysis SSD X-Max Inca Energy (JEOL, Japan; Oxford Instruments, Great Britain).

The total metal content in liquid media (acid solutions, wastewater) was determined by spectral analysis on a "Spectro-Sky" atomic emission spectrometer with magnetic plasma [12]. The content of $\mathrm{Fe}$ (II) and $\mathrm{Cr}$ (VI) ions in solutions and wastewater was carried out on a DR 2800 spectrometer (HACH USA).

\section{METODS OF EXPERIMENTS}

Samples of pre-ground slag were dissolved in hydrofluoric acid and the content of the main components was determined.

Titanium anodic etching solutions were analyzed for the content of the main components and the content of free sulfuric acid was determined.

Slag samples were treated with spent pickling solutions by changing the phase ratio (scale: acid) and the process temperature. Given the developed surface of the slag and the data of preliminary experiments, the optimal process time was 30 minutes. A further increase in processing time does not increase the degree of extraction of the main active component. The insoluble part was filtered off and the aqueous liquid phase was analyzed for the content of basic elements.

The effectiveness of the obtained solutions was evaluated on real wastewater of the plating deposition site containing chromium ( $\mathrm{VI}$ ) ions. Various doses of reagents were introduced into the wastewater, intensively mixed. Then, $\mathrm{pH}$ correction and filtration of precipitates were carried out. Purified wastewater was analyzed for chromium (VI) ions. The cleaning efficiency was calculated by the difference in the content of chromium ions (VIO in the source and purified water.

\section{RESULTS AND DISCOSSIONS}

Table 1 is dedicated the chemical composition of the sample averaged electric slag smelting process of steel produced in the manufacture of machinery. 
Table 1 Chemical composition of the sample slag

\begin{tabular}{|c|c|c|c|c|c|c|c|c|c|c|}
\hline Component & $\mathrm{SiO}_{2}$ & $\mathrm{CaO}$ & $\mathrm{P}$ & $\mathrm{S}$ & $\mathrm{Al}_{2} \mathrm{O}_{3}$ & $\mathrm{MnO}$ & $\mathrm{Cr}_{2} \mathrm{O}_{3}$ & $\mathrm{TiO}_{2}$ & $\mathrm{Fe}_{2} \mathrm{O}_{3}$ & $\mathrm{FeO}$ \\
\hline Content (wt\%) & 46.3 & 3.6 & 0.6 & 1.1 & 7.5 & 2.3 & 6.5 & 1.4 & 10.5 & 20.2 \\
\hline
\end{tabular}

From the data of Table 1 it can be seen that up to $30 \%$ of iron (II) and (III) compounds are present in the slag composition, which can be used to obtain a complex reducing coagulant.

At the next stage of the experiments, slag samples were processed with spent solutions of anodic etching of titanium. Sulfuric acid in the composition of the solutions will dissolve acid-soluble components (mainly iron oxides).

Table 2 is dedicated experimental parameters, as well as data on the content of active components in the solutions obtained during the processing of slag.

Table 2 Evaluation of the efficiency of iron extraction from slag depending on processing conditions

\begin{tabular}{|c|c|c|c|c|c|c|c|}
\hline \multirow[t]{2}{*}{ № } & \multirow[t]{2}{*}{ Ratio Slug: $\mathrm{H}_{2} \mathrm{SO}_{4}$} & \multirow[t]{2}{*}{ Temperature, ${ }^{\circ} \mathrm{C}$} & \multicolumn{3}{|c|}{$\begin{array}{c}\text { Metal content } \\
\text { (wt\%) }\end{array}$} & \multirow{2}{*}{$\begin{array}{c}\text { Free } \\
\mathrm{H}_{2} \mathrm{SO}_{4} \\
\text { (wt\%) }\end{array}$} & \multirow[t]{2}{*}{ Extraction (\%) } \\
\hline & & & Fe (total) & $\mathrm{Ti}$ (total) & $\mathrm{Fe}^{2+}$ & & \\
\hline \multicolumn{2}{|c|}{ Basic acid (no slag) } & - & 0.1 & 5.6 & 0.1 & 5.5 & - \\
\hline 1 & $1: 3$ & 40 & 4.20 & 5.6 & 1.44 & 2.93 & 41 \\
\hline 2 & $1: 3$ & 60 & 4.91 & 5.6 & 1.68 & 2.55 & 48 \\
\hline 3 & $1: 3$ & 80 & 5.53 & 5.6 & 1.89 & 2.22 & 54 \\
\hline 4 & $1: 4$ & 40 & 4.68 & 5.6 & 1.60 & 1.83 & 61 \\
\hline 5 & $1: 4$ & 60 & 5.37 & 5.6 & 1.84 & 1.34 & 70 \\
\hline 6 & $1: 4$ & 80 & 5.76 & 5.6 & 1.97 & 1.06 & 75 \\
\hline 7 & $1: 5$ & 40 & 4.79 & 5.6 & 1.64 & 0.90 & 78 \\
\hline 8 & $1: 5$ & 60 & 5.46 & 5.6 & 1.87 & 0.29 & 89 \\
\hline 9 & $1: 5$ & 80 & 5.89 & 5.6 & 2.02 & 0.12 & 96 \\
\hline 10 & $1: 6$ & 40 & 5.01 & 5.6 & 1.72 & 0.10 & 98 \\
\hline 11 & $1: 6$ & 60 & 5.12 & 5.6 & 1.75 & 0.10 & 99 \\
\hline 12 & $1: 6$ & 80 & 5.12 & 5.6 & 1.75 & 0.10 & 99 \\
\hline
\end{tabular}

The absence of calcium compounds in the solution can be explained by the formation of insoluble calcium fluoride and sulfate during the synthesis and its isolation in the form of an insoluble precipitate. Compounds of silicon, manganese, and chromium, nickel, and other metals were present in insignificant amounts $(<0.1 \%)$ in the solution, which is explained by the low activity of dilute sulfuric acid solutions with respect to these elements.

Based on the data at Table 2, it is seen that the optimal conditions for the synthesis of a complex coagulantreducing agent correspond to the conditions of experiment 10. The degree of extraction of the main components is maximum, while the process temperature is minimal. It is the solution of experiment 10 that will be used in the purification of wastewater from the galvanic site from chromium (VI) compounds.

The final stage of the experiments was the evaluation of the effectiveness of the obtained solutions of the complex coagulant-reducing agent. The compounds of titanium (IV) and iron (III) are responsible for the coagulation effect of the reagent, while the compounds of iron (II) will act as a reducing agent. Chemically pure 
iron (II) sulfate was used as a reference sample. Data on the efficiency of wastewater treatment, depending on the dose of a solution of a complex coagulant-reducing agent, are presented in Figure 1.

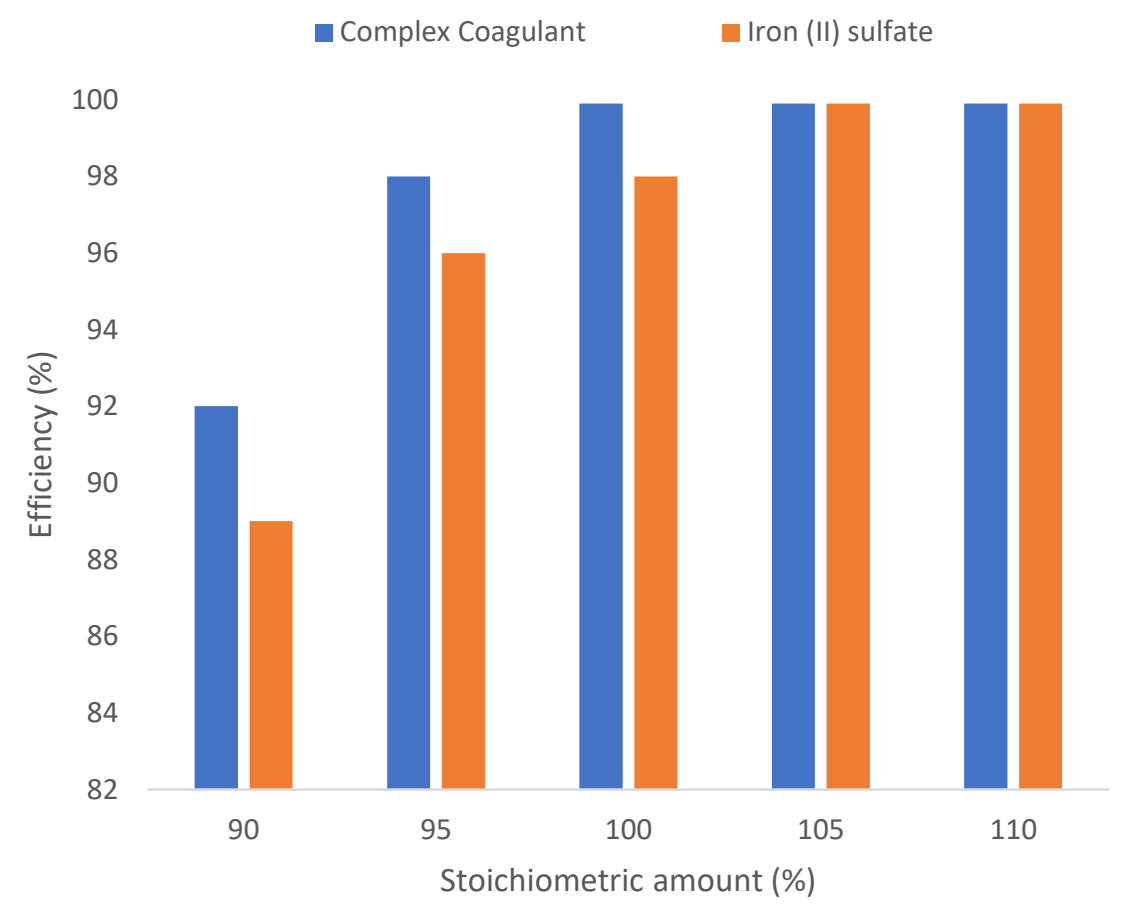

Figure 1 The effectiveness of water purification from chromium $(\mathrm{VI})$ by various reagents

From the data in Figure 1 it can be seen that the sample of the complex coagulant reducing agent is not inferior in its effectiveness to traditional reducing agents based on iron (II) sulfate. It should be noted that the raw materials for obtaining a complex coagulant reducing agent are waste from metallurgical and galvanic production, which means that the cost of this reagent will be significantly lower than that of pure reagents. Based on literature data, it can be assumed that the presence of titanium compounds in the complex coagulantreducing agent will have a positive effect on the filtration rate of precipitates formed.

\section{CONCLUSION}

As part of the work, a technology for the utilization of metallurgical slag with the production of a complex coagulant-reducing agent is proposed. The chemical composition of the slag was studied and the neutralization modes of the spent solutions of anodic etching of titanium with this slag were selected. It was found that to achieve the maximum degree of dissolution of the slag, it is necessary to maintain the slag: spent acid solution ratio of $1: 6$ and the reaction mixture heated to $40^{\circ} \mathrm{C}$. The data obtained as a result of the work will make it possible to organize the reuse of two wastes of metallurgical processes and reduce the negative impact on the environment.

\section{ACKNOWLEDGEMENTS}

This work was supported by the D. Mendeleev University of Chemical Technology of Russia through the Internal Bridging Grants for Young Science Educators Contest, proposal no. Z-2020-013.

\section{REFERENCES}

[1] GAO J.T., LI S.Q., ZHANG Y. T., ZHANG Y. L., CHEN P.Y., SHEN P. Process of Re-Resourcing of Converter Slag J Iron Steel Res Int. 2011, vol. 18, no. 2, pp.32-39. 
[2] SANAY J. S., NAGPAL O. P., PRASAD S. Waste management of steel slag. Steel Times International. 2000, no. 2, pp. 38-40, 43.

[3] MATINDE E.; SIMATE G.S.; NDLOVU S. Mining and metallurgical wastes: A review of recycling and re-use practices. J. South. Afr. Inst. Min. Metall. 2018, no. 118, pp. 825-844.

[4] MIHOK L., FEDICOVA D. Recycling of demetallized steelmaking slag into charge of basic oxygen converter Metallurgija. 2000, no. 2, pp. 93-99.

[5] LI Y. Recycling techniques of steel slag and its utilization in green concrete to enhance properties and durability. In: 5th International Conference on Responsive Manufacturing - Green Manufacturing. Ningbo, 2010, pp. 463468.

[6] VINOGRADOV C.C. Environmentally friendly galvanic production. Moscow: GLOBUS, 1998.

[7] VEMULA Madhavi, REDDY Ambavaram Vijay Bhaskar, REDDY Kalluru Gangadhara, MADHAVI Gajulapalle, et.al. An overview on research trends in remediation of chromium. Research Journal of Recent Sciences. 2013, vol. 2, pp. 71-83.

[8] KUZIN E.N., AVERINA Y. M., KURBATOV A. Yu., SAHAROV P. A. Wastewater treatment of galvanic production using complex reducing coagulants. Tsvetnye metally. 2019, no. 10, pp. 91-96.

[9] KUZIN E.N., CHERNYSHEV P.I., VIZEN N.S., KRUTCHININA N.E. The Purification of the Galvanic Industry Wastewater of Chromium (VI) Compounds Using Titanium(III) Chloride. Russian Journal of General Chemistry. 2018, vol. 88, no. 13, pp. 2954-2957.

[10] GALLOUX J., CHEKLI L., PHUNTSHO S., TIJING L. D., JEONG S., ZHAOY. X., GAO B. Y., PARK S. H., SHON H. K. Coagulation performance and floc characteristics of polytitanium tetrachloride and titanium tetrachloride compared with ferric chloride for coal mining wastewater treatment. Sep. Purif. Technol. 2015, no. 152, pp. 94100.

[11] ZHAO Y. X., GAO B. Y., ZHANG G. Z., QI Q. B., WANG Y., PHUNTSHO S., KIM J.-H., SHON H. K., YUE Q. Y., LI Q. Coagulation and sludge recovery using titanium tetrachloride as coagulant for real water treatment: $A$ comparison against traditional aluminum and iron salts. Separation and Purification Technology. 2014, vol. 130, pp. 19-27.

[12] KUCHIUMOV V.A., SHUMKIN S.S. Analysis of the chemical composition of the initial alloy in the production of permanent magnets from system alloys Sm-Co. Scientific and technical statements of SPbSPU. 2017, vol. 23, no 1, pp. 219-225. 